Jurnal Dinamika Sosial Ekonomi Vol.20 No.1, Juni 2019 : 81-95

ISSN 1411-593X (print)

\title{
ANALISIS RISIKO PRODUKSI DAUN TEH BASAH BERDASARKAN PEMETIKAN MEKANIK DAN MANUAL PADA PT PERKEBUNAN NUSANTARA IX KEBUN SEMUGIH KABUPATEN PEMALANG
}

\author{
Production Risk Analysis of Raw Tea Based on Machine and Manual Picking \\ in PT Perkebunan Nusantara IX Semugih Pemalang District \\ Luluk Hamidiyati Ula*, Ni Made Suyastiri, Heni Handri Utami \\ Program Studi Agribisnis Fakultas Pertanian \\ Universitas Pembangunan Nasional "Veteran" Yogyakarta \\ Jl. SWK No.104, Kabupaten Sleman, Daerah Istimewa Yogyakarta 55283 \\ email korespondensi : lulukhamidiyati@gmail.com
}

Diterima tanggal : 6 Maret 2019 ; Disetujui tanggal : 21 Mei 2019

\begin{abstract}
This study aims to analyze the differences in the risk of production of wet tea leaves on mechanical and manual picking, analyze differences in labor productivity of mechanical and manual picking, and analyze and recommend strategies for handling the risk of mechanical and manual picking production at PT Perkebunan Nusantara IX Kebun Semugih. The research method used is descriptive quantitative research with a case study method. Techniques for collecting data through observation, interviews and literature. Data analysis techniques used are coefficient of variation, $Z$ test and risk map for strategy determination. The results of this study are 1) differences in the risk value of mechanical and manual picking production of 0.09. The risk value of wet tea leaf production at mechanical picking was 0.76 and the risk value of manual tea leaf production was 0.67. 2) differences in mechanical and manual picking work productivity of $24.28 \mathrm{~kg} / \mathrm{jko}$. Mechanical picking productivity is $31.52 \mathrm{~kg} / \mathrm{jko}$ and manual picking productivity is $7.24 \mathrm{~kg} / \mathrm{jko}$. 3) The right risk strategy to handle the risk of mechanical picking on the risk source of picking skills is a combined strategy of mitigation and prevention by reducing the impact and preventing the risk from occurring, while the strategy of fatigue and engine damage is not handled. The risk strategy to handle the risk of manual picking on the source of risk of picking power fatigue uses a combined strategy of mitigation and preventive action, while the risk of picking skills is not handled by the strategy.
\end{abstract}

Keywords : labor productivity, manual picking, mechanical picking, production risk, risk map, risk strategy

\footnotetext{
ABSTRAK

Penelitian ini bertujuan untuk menganalisis perbedaan risiko produksi daun teh basah pada pemetikan mekanik dan manual, menganalisis perbedaan produktivitas
} 
tenaga kerja pemetikan mekanik dan manual, serta menganalisis dan merekomendasikan strategi penanganan risiko produksi pemetikan mekanik dan manual di PT Perkebunan Nusantara IX Kebun Semugih. Metode penelitian yang digunakan adalah penelitian deskriptif kuantitatif dengan metode studi kasus. Teknik pengumpulan data melalui observasi, wawancara dan studi pustaka. Teknik analisis data yang digunakan yaitu koefisien variasi, uji $\mathrm{Z}$ dan peta risiko untuk penentuan strategi. Hasil penelitian ini adalah 1) perbedaan nilai risiko produksi pemetikan mekanik dan manual sebesar 0,09. Nilai risiko produksi daun teh basah pada pemetikan mekanik sebesar 0,76 dan nilai risiko produksi daun teh basah pemetikan manual sebesar 0,67.2) perbedaan produktivitas kerja pemetikan mekanik dan manual sebesar 24,28 kg/jko. Produktivitas pemetikan mekanik sebesar 31,52 kg/jko dan produktivitas pemetikan manual sebesar 7,24 kg/jko. 3) Strategi risiko yang tepat untuk menangani risiko pemetikan mekanik pada sumber risiko keterampilan pemetik yaitu strategi gabungan antara mitigasi dan preventif dengan mengurangi dampak dan mencegah risiko itu terjadi, sedangkan risiko kelelahan dan kerusakan mesin tidak dilakukan penanganan strategi. Strategi risiko untuk menangani risiko pemetikan manual pada sumber risiko kelelahan tenaga pemetik menggunakan strategi gabungan antara mitigasi dan preventif, sedangkan risiko keterampilan pemetik tidak dilakukan penanganan strategi.

Kata kunci : produktivitas tenaga kerja, pemetikan manual, pemetikan mekanik, risiko produksi, peta risiko, strategi risiko.

\section{PENDAHULUAN}

Proses budidaya tanaman teh dalah kegiatan yang padat tenaga kerja (Dalimonthe dan Kartawijaya, 1997) dan salah satu tenaga kerja yang paling berpengaruh adalah tenaga kerja pemetikan. Pemetikan memiliki kontribusi yang besar dalam produksi teh yaitu mencapai $70 \%$. Dengen memperhatikan peran kegiatan pemetikan, maka produksi akan optimal (Sukasman, 1998). Tenaga kerja pemetikan teh adalah salah satu faktor yang paling penting bagi suatu perusahaan agribisnis perkebunan teh (Ongong dan Ochieng, 2013).

Kebutuhan tenaga kerja di kebun teh rata-rata 1 orang per hektar. Dari jumlah tersebut $70 \%$ merupakan tenaga kerja pemetikan. Pengembangan pemetikan secara mekanis dikembangkan untuk menanggulangi adanya kelangkaan tenaga kerja pemetikan sehingga diharapkan kualitas pucuk teh yang dipetik tetap terjaga. Risiko berhubungan dengan ketidakpastian, hal ini terjadi akibat dari kurangnya atau tidak terjadinya informasi yang menyangkut apa yang akan terjadi. Ketidakpastian yang dihadapi perusahaan dapat berdampak 
Ula et.al. / Jurnal Dinamika Sosial Ekonomi Vol.20 No.1, Juni 2019

merugikan atau menguntungkan. Apabila ketidakpastian yang dihadapi perusahaan dapat berdampak menguntungkan maka disebut dengan istilah kesempatan (opportunity), sedangkan ketidakpastian yang berdampak merugikan disebut sebagai risiko (Kountur, 2008). Peta risiko merupakan salah satu cara yang dapat digunakan sebelum menentukan manajemen risiko. Dengan menggunakan peta risiko tersebut, diharapkan lebih memudahkan seorang manager atau pemilik usaha dalam menentukan cara penanganan yang tepat terhadap risiko yang dialami (Kountur, 2008).

Salah satu perusahaan perkebunan teh negara yang berada di Jawa Tengah adalah PT Perkebunan Nusantara IX Kebun Semugih yang berlokasi di Kecamatan Moga, Kabupaten Pemalang. PT Perkebunan Nusantara IX Kebun Semugih merupakan perkebunan teh yang berada di ketinggian 600-700 mdpl, di sebelah utara Gunung Slamet. PT Perkebunan Nusantara IX Kebun Semugih memiliki luas 415 ha. Metode pemetikan yang dilakukan di PT Perkebunan Nusantara IX Kebun Semugih menggunakan dua metode yaitu petik mesin dan petik tangan atau manual. Luas areal yang digunakan untuk petik mesin sebesar 19,6 ha sedangkan sisanya seluas 384,4 ha menggunakan metode petik tangan.

Penelitian ini bertujuan untuk menganalisis perbedaan risiko produksi daun teh basah pada pemetikan mekanik dan manual, menganalisis perbedaan produktivitas tenaga kerja pemetikan mekanik dan manual, dan menganalisis dan merekomendasikan strategi penanganan risiko produksi daun teh basah pada pemetik mekanik dan manual di PT Perkebunan Nusantara IX Kebun Semugih.

\section{METODE PENELITIAN}

Penelititan ini dilaksanakan di PT Perkebunan Nusantara IX Kebun Semugih, Kabupaten Pemalang. Metode yang digunakan dalam penelitian ini adalah metode deskriptif studi kasus. Penentuan responden dalam penelitian ini menggunakan metode purposive sampling, dipilih 3 orang yaitu manager Kebun Semugih, koordinator lapangan, dan Asisten Kebun. Metode pengumpulan data yang digunakan adalah wawancara, observasi dan studi pustaka. 
Teknik analisis yang digunakan yaitu analisis risiko produksi, analisis produktivitas tenaga kerja, dan pemetaan risiko.

1. Analisis Risiko

Risiko produksi daun teh basah pada PT Perkebunan Nusantara IX Kebun Semugih dihitung menggunakan koefisien variasi dengan rumus :

$$
C V=\frac{\sigma}{E}
$$

Keterangan :

$\mathrm{CV}=$ Koefisien variasi risiko produksi daun teh basah

$\sigma=$ standar deviasi risiko produksi daun teh basah

$E \quad=$ rata-rata hasil produksi daun teh basah

Rumusan Hipotesisnya adalah :

Ho : rata-rata produksi daun teh basah pemetikan mekanik = rata-rata produksi daun teh basah pemetikan manual

H1 : rata-rata produksi daun teh basah pemetikan mekanik $\neq$ rata-rata produksi daun teh basah pemetikan manual

\section{Analisis Produktivitas Tenaga Kerja}

Analisis produktivitas tenaga kerja dihitung menggunakan rumus produktivitas dengan membagi antara hasil produksi daun teh basah dengan jam kerja orang.

$$
\text { produktivitas tenaga kerja }=\frac{\text { produksi daun teh basah }(\mathrm{kg})}{\text { jam kerja orang }(j \mathrm{ko})}
$$

Rumusan hipotesisnya :

Ho : produktivitas tenaga kerja pemetikan mekanik = produktivitas tenaga kerja pemetikan manual

H1 : produktivitas tenaga kerja pemetikan mekanik $\neq$ produktivitas tenaga kerja pemetikan manual

\section{Pemetaan Risiko}

Peta risiko adalah gambaran tentang posisi risiko pada suatu peta dari dua sumbu yaitu sumbu vertikal menggambarkan probabilitas, dan sumbu 
horizontal menggambarkan dampak. Untuk menghitung probabilitas risiko menggunakan z-score dengan rumus :

$z=\frac{x-\bar{x}}{s}$

Keterangan :

$\mathrm{z} \quad=$ nilai $\mathrm{z}$ (atau $\mathrm{z}$-score)/ nilai probabilitas

$\mathrm{x} \quad$ = batas kegagalan produksi daun teh basah

$\bar{x} \quad=$ rata-rata produksi daun teh basah

$s \quad=$ standar deviasi

Sedangkan untuk mengukur dampak risiko menggunakan VaR. Value at Risk (VaR) merupakan suatu metode yang digunakan untuk mengukur besarnya akibat dari suatu risiko.

$V a R=\bar{x}+z\left(\frac{s}{\sqrt{n}}\right)$

Keterangan :

VaR = dampak Kerugian $(\mathrm{Rp})$

$\bar{x} \quad=$ rata-rata kerugian pemetikan daun teh basah

$z \quad=$ tingkat toleransi $5 \%$

$s \quad=$ standar deviasi

$n \quad$ = periode panen/pemetikan daun teh basah

\section{HASIL DAN PEMBAHASAN}

\section{Analisis Risiko Produksi Daun Teh Basah}

PT Perkebunan Nusantara IX Kebun Semugih dalam melakukan pemetikan dihadapkan pada ketinggalan daun yang tidak terpetik dan kerusakan daun pada setiap periode petikan sehingga dapat mengurangi produksi pucuk teh yang dihasilkan dan dapat mempengaruhi hasil produksi pada periode pemetikan selanjutnya. Adapun risiko produksi pada setiap teknik pemetikan itu berbeda. Pada pemetikan mekanik risiko yang sering terjadi adalah pucuk belum masuk petik (pucuk yang belum boleh dipetik), daun tua, rumput, gulma dan ranting ikut terbawa sehingga perlu dilakukan sortasi basah. Areal tidak rata dan daun rusak 
akibat salah satu pisau putus atau tenaga kerja memiringkan handle mesin dan wadah/waring saat pemetikan berlangsung. Sedangkan risiko yang terjadi pada pemetikan manual adalah kerataan perdu tidak terjaga, petikan banyak tertinggal, dan pemetikan tidak sempurna yang dapat menyebabkan daun rusak dan mengurangi nilai analisa.

Tabel 2. Hasil Produksi daun teh basah dan Nilai Koefisien Variasi pada Pemetikan Mekanik dan Manual PT Perkebunan Nusantara IX Kebun Semugih Bulan Januari-Desember 2018

\begin{tabular}{lcrrrr}
\hline $\begin{array}{c}\text { Metode } \\
\text { Pemetikan }\end{array}$ & $\begin{array}{c}\text { Produksi } \\
(\mathrm{kg})\end{array}$ & $\begin{array}{c}\text { Luas Lahan } \\
\text { (ha) }\end{array}$ & $\begin{array}{c}\text { Rata-rata } \\
\text { Produksi }(\mathrm{kg})\end{array}$ & $\begin{array}{c}\text { Standar } \\
\text { Deviasi }\end{array}$ & $\begin{array}{c}\text { Koefisien } \\
\text { variasi }\end{array}$ \\
\hline Mekanik & 183.464 & 19,36 & $5.096,00$ & 551,09 & 0,76 \\
Manual & 195.034 & 23,05 & $5.425,61$ & 458,17 & 0,67 \\
\hline
\end{tabular}

Sumber: Analisis Data Primer, 2019

Berdasarkan Tabel 2. menunjukkan bahwa jumlah produksi teh pada bulan Januari hingga Desember 2018 dengan pemetikan mekanik sebesar $183.464 \mathrm{~kg}$ dengan luasan 19,36 ha, sedangkan pada pemetikan manual sebesar $195.034 \mathrm{~kg}$ dengan luasan 23,05 ha. Pemetikan mekanik mempunyai rata-rata produksi 5.096 $\mathrm{kg}$ dan standar deviasi dari sebesar 551,09. Rata-rata produksi pemetikan manual 5.425,61 kg dan standar deviasi sebesar 458,17. Hasil dari standar deviasi pada pemetikan mekanik dan pemetikan manual mencerminkan adanya penyimpangan yang sangat tinggi. Semakin besar nilai standar deviasi maka data sampel semakin menyebar (bervariasi) dari rata-ratanya, sehingga semakin besar nilai standar deviasi maka semakin besar risiko yang dihadapi dan semakin kecil nilai standar deviasi maka semakin besar risiko yang dihadapi.

Berdasarkan tabel 2, diperoleh nilai koefisien variasi pemetikan teh dengan mekanik sebesar 0,76 menunjukkan bahwa apabila terjadi penurunan produksi akibat pemetikan mekanik maka risiko produksi daun teh basah dihadapi oleh perusahaan sebesar $76 \%$. Nilai koefisien variasi pemetikan manual sebesar 0,67 menunjukkan bahwa apabila terjadi penurunan produksi daun teh basah akibat pemetikan manual maka nilai risiko produksi yang dihadapi oleh perusahaan akibat risiko pemetikan manual sebesar $67 \%$. 
Ula et.al. / Jurnal Dinamika Sosial Ekonomi Vol.20 No.1, Juni 2019

Hasil perhitungan menggunakan SPSS pada tabel 3 diketahui sig. (2tailed) 0,206 > 0,05 (alpha) maka ho ditolak artinya tidak terdapat perbedaan nilai risiko produksi teh basah antara pemetikan mekanik dan pemetikan manual. Berdasarkan hasil pengujian tidak terdapat perbedaan nilai risiko produksi daun teh basah pada pemetikan mekanik dan manual yang dibuktikan dengan nilai koefisien variasi dari pemetikan mekanik dan manual dengan perbedaan nilai sebesar 0,09 (perbedaannya sedikit). Hal ini dikarenakan risiko produksi daun teh basah pada pemetikan mekanik dan pemetikan manual di PT Perkebunan Nusantara IX Kebun Semugih sama-sama tinggi.

Tabel 3. Hasil Pengujian Hipotesis Pertama

\begin{tabular}{|c|c|c|c|c|c|c|c|}
\hline \multicolumn{5}{|c|}{ Paired Differences } & \multirow[t]{3}{*}{$t$} & \multirow[t]{3}{*}{$d f$} & \multirow{3}{*}{$\begin{array}{l}\text { Sig. }(2- \\
\text { tailed })\end{array}$} \\
\hline \multirow[t]{2}{*}{ Mean } & \multirow[t]{2}{*}{$\begin{array}{c}\text { Std. } \\
\text { Deviation }\end{array}$} & \multirow[t]{2}{*}{$\begin{array}{l}\text { Std. } \\
\text { Error } \\
\text { Mean }\end{array}$} & \multicolumn{2}{|c|}{$\begin{array}{c}95 \% \text { Confidence } \\
\text { Interval of the } \\
\text { Difference }\end{array}$} & & & \\
\hline & & & Lower & Upper & & & \\
\hline 96,902 & 450,912 & 75,152 & $-55,664$ & 249,469 & 1,289 & 35 & 206 \\
\hline
\end{tabular}

Sumber: Analisis Data Primer, 2019

\section{Analisis Produktivitas Tenaga Kerja}

Produktivitas merupakan perbandingan antara hasil yang dicapai dengan peran serta tenaga kerja per satuan waktu. Produktivitas juga dapat diartikan sebagai alat ukur bagi perusahaan dalam menilai prestasi kerja yang dicapai karyawannya. Setiap perusahaan pasti menginginkan hasil produksinya tinggi namun tetap efisien. Pada PT Perkebunan IX Kebun Semugih ini mulai melakukan pemetikan mekanik untuk meningkatkan produktivitas dan efisiensinya.

Tabel 4. Produktivitas Tenaga Kerja Pemetikan Mekanik dan Manual PT Perkebunan Nusantara IX Kebun

\begin{tabular}{|c|c|c|c|}
\hline & $\begin{array}{l}\text { Produksi } \\
(\mathrm{kg})\end{array}$ & $\begin{array}{l}\text { Jam kerja } \\
\text { orang (jko) }\end{array}$ & $\begin{array}{l}\text { Produktivitas Tenaga Kerja } \\
(\mathrm{kg} / \mathrm{jko})\end{array}$ \\
\hline $\begin{array}{l}\text { Pemetikan } \\
\text { Mekanik }\end{array}$ & 183.464 & 5.820 & 31,52 \\
\hline $\begin{array}{l}\text { Pemetikan } \\
\text { Manual }\end{array}$ & 191.875 & 26.415 & 7,24 \\
\hline
\end{tabular}


Berdasarkan tabel 4. hasil produktivitas tenaga kerja pada pemetikan mekanik sebesar $31,52 \mathrm{~kg} / \mathrm{jko}$ sedangkan produktivitas tenaga kerja pemetikan manual sebanyak 7,24 kg/jko. Produktivitas pemetikan mekanik 4 kali lipat dari produktivitas pemetikan manual. Hasil tersebut menunjukkan bahwa pemetikan mekanik lebih efisien dibandingkan pemetikan manual. PT Perkebunan Nusantara IX Kebun Semugih juga dapat menekan biaya tenaga kerja apabila pemetikan mekanik dapat diaplikasikan pada semua blok kebun. Menurut Johan dan Sriyadi (2005) pemetikan dengan menggunakan gunting petik dan siklus petik panjang dapat meningkatkan potensi hasil yang optimal.

Tabel 5. Hasil Pengujian Hipotesis Kedua

\begin{tabular}{|c|c|c|c|c|c|c|c|}
\hline \multicolumn{5}{|c|}{ Paired Differences } & \multirow[t]{3}{*}{$t$} & \multirow[t]{3}{*}{$d f$} & \multirow{3}{*}{$\begin{array}{l}\text { Sig. } \\
(2- \\
\text { tailed })\end{array}$} \\
\hline \multirow[t]{2}{*}{ Mean } & \multirow[t]{2}{*}{$\begin{array}{c}\text { Std. } \\
\text { Deviation }\end{array}$} & \multirow[t]{2}{*}{$\begin{array}{l}\text { Std. } \\
\text { Error } \\
\text { Mean }\end{array}$} & \multicolumn{2}{|c|}{$\begin{array}{l}\text { 95\% Confidence } \\
\text { Interval of the } \\
\text { Difference }\end{array}$} & & & \\
\hline & & & Lower & Upper & & & \\
\hline 5,070 & 5,365 & 0,894 & 3,255 & 6,886 & 5,670 & 35 & 000 \\
\hline
\end{tabular}

Sumber: Analisis Data Primer, 2019

Hasil perhitungan menggunakan SPSS diketahui nilai sig. (2-tailed) $0,00<$ 0,05 (alpha) maka ho ditolak yang artinya terdapat perbedaan antara produktivitas tenaga kerja pada pemetikan mekanik dan pemetikan manual. Produktivitas tenaga kerja pada pemetikan manual lebih kecil dibandingkan dengan produktivitas tenaga kerja pada pemetikan mekanik. Hal itu terjadi karena tenaga kerja pemetikan manual mayoritas ibu-ibu, sehingga tingkat kelelahannya lebih tinggi dibandingkan tenaga kerja pemetikan mekanik yang berjenis kelamin lakilaki. Pada PT Perkebunan Nusantara IX Kebun Semugih sendiri sering terjadi kekurangan tenaga kerja pada blok pemetikan manual, sehingga terjadi penambahan waktu untuk proses pemetikan. Oleh karena itu PT Perkebunan Nusantara IX Kebun Semugih perlu melakukan kebijakan dan evaluasi mengenai tenaga kerja pemetikan manual agar tidak terjadi kekurangan tenaga kerja lagi yang dapat menurunkan produktivitas tenaga kerja. 
Ula et.al. / Jurnal Dinamika Sosial Ekonomi Vol.20 No.1, Juni 2019

\section{Pemetaan Risiko}

Tujuan utama dari manajemen risiko adalah untuk dapat meningkatkan semaksimal mungkin keuntungan perusahaan. Apabila risiko yang ditimbulkan dari teknik pemetikan teh dapat menurunkan hasil produksi atau bahkan merugikan perusahaan maka perlu penanganan risiko. Sebelum menangani risiko yang terjadi, yang terlebih dahulu dilakukan adalah mengidentifikasi sumber resiko dengan membuat peta risiko. Peta risiko adalah gambaran tentang posisi risiko pada suatu peta dari dua sumbu yaitu sumbu vertikal menggambarkan probabilitas, dan sumbu horizontal menggambarkan dampak.

Analisis probabilitas risiko digunakan untuk mengetahui seberapa besar probabilitas atau kemungkinan terjadinya risiko. Data-data yang digunakan untuk melakukan analisis probabilitas adalah data produksi pemetikan mekanik dan pemetikan manual selama tahun 2018 (Januari-Desember 2018), dan hasil wawancara dengan pihak PT Perkebunan Nusantara IX Kebun Semugih. Perhitungan analisis probabilitas terjadinya risiko produksi diolah dengan menggunakan nilai standar atau z-score.

Tabel 6. Probabilitas Risiko Produksi Daun Teh Basah pada Pemetikan Mekanik dan Manual di PT Perkebunan Nusantara IX Kebun Semugih

\begin{tabular}{lclcl}
\hline \multirow{2}{*}{ Risiko } & \multicolumn{2}{c}{ Pemetikan Mekanik } & \multicolumn{2}{c}{ Pemetikan Manual } \\
\cline { 2 - 5 } & $\begin{array}{c}\text { Probabilitas } \\
(\%)\end{array}$ & Kategori & $\begin{array}{c}\text { Probabilitas } \\
(\%)\end{array}$ & Kategori \\
\hline Keterampilan Pemetik & 59 & $\begin{array}{l}\text { Risiko } \\
\text { besar }\end{array}$ & 27 & $\begin{array}{l}\text { Risiko } \\
\text { kecil } \\
\text { Kelelahan pemetik }\end{array}$ \\
Rerusakan mesin & 24 & $\begin{array}{l}\text { Risiko } \\
\text { kecil }\end{array}$ & 54 & $\begin{array}{l}\text { Risiko } \\
\text { besar }\end{array}$ \\
Risiko & - & - \\
\hline
\end{tabular}

Sumber: Analisis Data Primer, 2019

Probabilitas risiko keterampilan pemetik pada metode pemetikan mekanik lebih tinggi dibandingkan dengan keterampilan pemetik pada pemetikan manual. Hal tersebut dikarenakan dalam pemetikan menggunakan mesin atau pemetikan mekanik membutuhkan skill yang tinggi sehingga hasil produksi dapat sesuai dengan mutu standar yang ditentukan oleh perusahaan. Pada risiko kelelahan pemetik dengan metode pemetikan mekanik lebih rendah dibandingkan dengan 
kelelahan pemetik pada metode pemetikan manual. Sedangkan risiko kerusakan mesin pada metode pemetikan mekanik tergolong dalam risiko rendah.

Penentuan probabilitas/kemungkinan terjadinya risiko pada keterampilan pemetik dapat diukur berdasarkan analisa pemetikan untuk mengevaluasi pelaksanaan pemetikan setiap hari, baik dari segi cara memetik maupun hasil petikkan, perlu dilakukan analisa pemetikan yang terdiri dari analisa petik dan dan analisa pucuk. Pada pemetikan mekanik, evaluasi dari keterampilan pemetikan hanya diukur berdasarkan analisa pucuk, sedangkan untuk pemetikan manual dilihat dari hasil pengukuran analisa petik dan pucuk. Analisa petik yaitu pemisahan bagian pucuk hasil suatu pemetikan yang didasarkan pada jenis pucuk yang dinyatakan persen. Analisa ini dilakukan dengan memisahkan beberapa jenis pucuk berdasarkan rumus petik. Dari hasil analisa keterampilan pemetik dinilai terampil apabila persentase pucuk belum masak $(\mathrm{P}+1, \mathrm{P}+2 \mathrm{~m})<3 \%$ dan dilapangan bekas bidang petik tidak banyak meninggalkan pucuk masuk petik dan pucuk burung.

Analisa pucuk yaitu pemisahan bagian pucuk hasil suatu pemetikan yang didasarkan pada bagian daun tua dan muda yang dinyatakan dalam persen. Analisa ini dilakukan dengan mengambil sampel pucuk pada setiap kemandoran sebanyak 200 gram dan dipisahkan menjadi tiga bagian yaitu daun muda, daun tua, dan rusak. Dari masing-masing kriteria tersebut ditimbang dan dihitung presentasenya. Hasil analisa pucuk yang baik yaitu apabila nilai MS (mutu standar) lebih dari 50\%. Probabilitas risiko keterampilan pemetik pada pemetikan mekanik lebih tinggi dibandingkan dengan pemetikan manual. Hal tersebut dibuktikan dengan nilai mutu standar pemetikan mekanik yang lebih kecil yaitu antara $48-50 \%$ sedangkan mutu standar pemetikan manual sebesar $50-56 \%$.

Risiko kelelahan pada tenaga petik mekanik memiliki probabilitas atau risiko yang lebih rendah dari pemetikan manual. Tenaga pemetik pada pemetikan mekanik berjenis kelamin laki-laki dan pada pemetikan manual berjenis kelamin perempuan. Tenaga kerja pemetikan manual yang mayoritas adalah ibu-ibu menyebabkan mereka lebih cepat merasa lelah, sehingga disaat mereka kelelahan dapat mengakibatkan penurunan hasil produksi yang mereka peroleh. 
Ula et.al. / Jurnal Dinamika Sosial Ekonomi Vol.20 No.1, Juni 2019

Risiko kerusakan mesin hanya dialami oleh pemetikan mekanik. Probabilitas kerusakan mesin ini seharusnya sangat kecil dibawah 15\% karena mesin pemetikan itu menjadi hak milik tenaga petik, dan apabila terjadi kerusakan akan ditanggung oleh tenaga petik itu sendiri sehingga mereka merawat mesin itu dengan baik. Akan tetapi jika terjadi kerusakan mesin perusahaan juga ikut mengalami kerugian karena proses produksi/pemetikan menjadi terhambat atau bisa jadi pemetikan mesin akan digantikan dengan pemetikan manual/gunting dan secara otomatis akan menambah tenaga kerja.

Dampak kerugian yang diakibatkan oleh risiko pemetikan mekanik dan pemetikan manual dapat dihitung dan dinilai dalam satuan mata uang (Rupiah), sehingga kerugian dapat diketahui dan diperkirakan sebagai akibat dari sumbersumber risiko pemetikan. Jika risiko produksi tersebut terjadi maka dilakukan penetapan besarnya kerugian. Perhitungan dampak risiko produksi pada pemetikan mekanik dan manual PT Perkebunan Nusantara IX Kebun Semugih menggunakan metode Value at Risk (VaR).

Tabel 7. Dampak Kerugian Pemetikan Mekanik dan Pemetikan Manual

\begin{tabular}{lrlcl}
\hline \multirow{2}{*}{ Risiko } & \multicolumn{2}{c}{ Pemetikan Mekanik } & \multicolumn{2}{c}{ Pemetikan Manual } \\
\cline { 2 - 5 } & Dampak (Rp) & Kategori & Dampak (Rp) & Kategori \\
\hline Keterampilan Pemetik & $6.961 .048,34$ & $\begin{array}{l}\text { Risiko } \\
\text { besar }\end{array}$ & $1.367 .015,99$ & $\begin{array}{l}\text { Risiko } \\
\text { kecil }\end{array}$ \\
Kelelahan pemetik & $1.305 .196,56$ & Risiko kecil & $7.746 .423,94$ & $\begin{array}{l}\text { Risiko } \\
\text { besar }\end{array}$ \\
Kerusakan mesin & $435.065,52$ & Risiko kecil & - & - \\
\hline
\end{tabular}

Sumber: Analisis Data Primer, 2019

Dampak kerugian dari keterampilan pemetik pada pemetikan mekanik dan lebih besar dari pemetikan manual. Keterampilan pemetik masuk dalam kategori risiko besar. Hal ini dikarenakan keterampilan pemetik sangat dibutuhkan agar dapat memperoleh hasil produksi yang tinggi. Apabila keterampilan pemetik rendah, maka hasil produksi yang didapat juga rendah sehingga dapat merugikan perusahaan.

Dampak kerugian dari kelelahan pemetik pada pemetikan mekanik lebih kecil daripada pemetikan manual. Apabila pemetik pada pemetikan mekanik 
mengalami kelelahan sehingga pemetik menurunkan atau memiringkan mesin pada saat proses pemetikan berlangsung dapat mengakibatkan penurunan bidang petik dan mengurangi daun pemeliharaan. Daun pemeliharaan berfungsi untuk penyangga atau dapur produsen (proses fotosintesis) pucuk. Manajemen petik harus mempertahankan jumlah daun pemeliharaan agar berada tetap ideal sehingga bisa menghasilkan pertumbuhan pucuk yang optimal. Kerusakan mesin pada pemetikan mekanik juga memiliki dampak yang kecil.

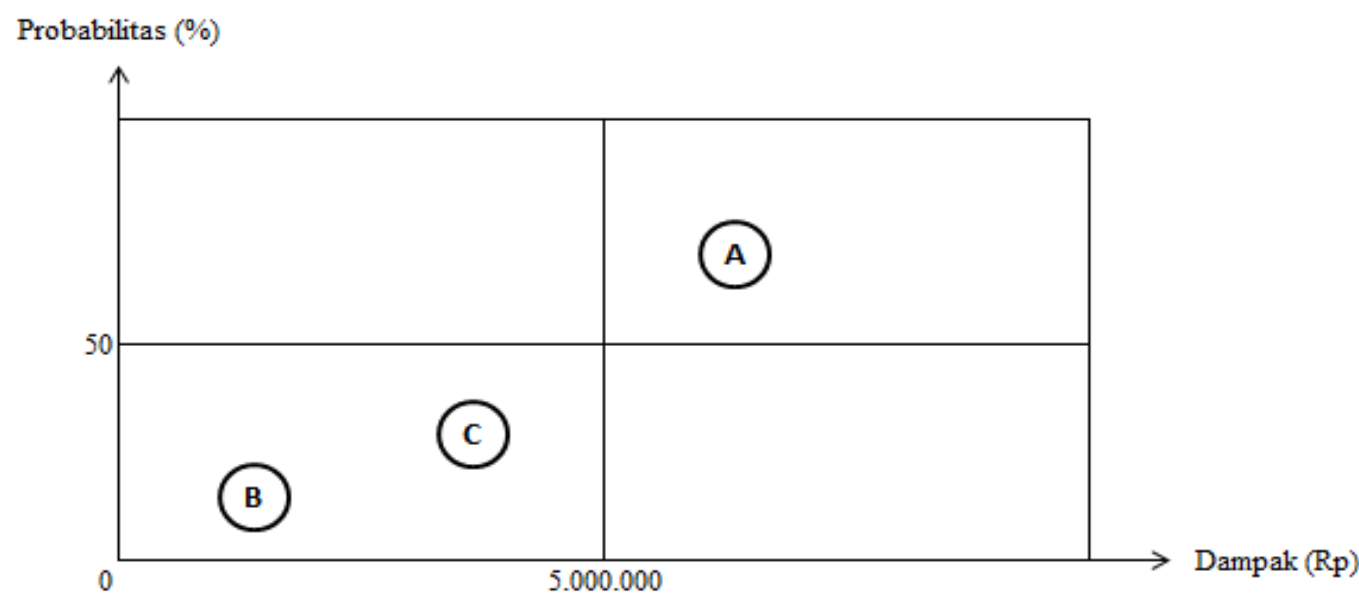

Gambar 1. Peta Risiko Pemetikan Mekanik

Keterangan :
A $\quad=$ Keterampilan Pemetik
B $\quad=$ Kelelahan Pemetik
$\mathrm{C} \quad=$ Kerusakan Mesin

Berdasarkan hasil dari pemetaan, risiko keterampilan pemetik berada pada kuadran dua (KW 2), risiko kelelahan pemetik berada pada kuadran tiga (KW 3), dan risiko kerusakan mesin berada pada kuadran tiga (KW 3).

Strategi alternatif yang digunakan untuk mengurangi risiko keterampilan pemetik pada pemetikan mekanik adalah gabungan dari strategi mitigasi dan preventif (mencegah dan mengurangi kerugian). Posisi risiko keterampilan pemetik yang berada pada kuadran 2 ditarik turun dan bergeser ke kuadran tiga. Usaha-usaha pencegahan dan usaha-usaha pengurangan risiko hanya dilakukan selama biaya pengelolaan risiko lebih kecil dari kerugian risiko. Pencegahan dan pengurangan kerugian pada risiko keterampilan pemetik dapat dilakukan dengan memperbaiki sistem kerja pada pemetik dan memperbaiki sumberdaya 
manusianya dengan dilakukannya pelatihan pemetikan menggunakan mesin. Sistem kerja yang borongan mengakibatkan pemetik hanya mengejar banyaknya hasil produksi tanpa memperdulikan mutu standar petikan, sehingga hal tersebut mengakibatkan kerugian pada perusahaan.

Berdasarkan gambar peta risiko kelelahan pemetik dengan metode pemetikan mekanik terletak pada kuadran tiga. Risiko kelelahan pemetik memiliki probabilitas yang kecil dan dampak yang kecil, sehingga tidak perlu dilakukan strategi mitigasi maupun preventif untuk memperkecil probabilitas dan mengurangi dampak risiko tersebut.

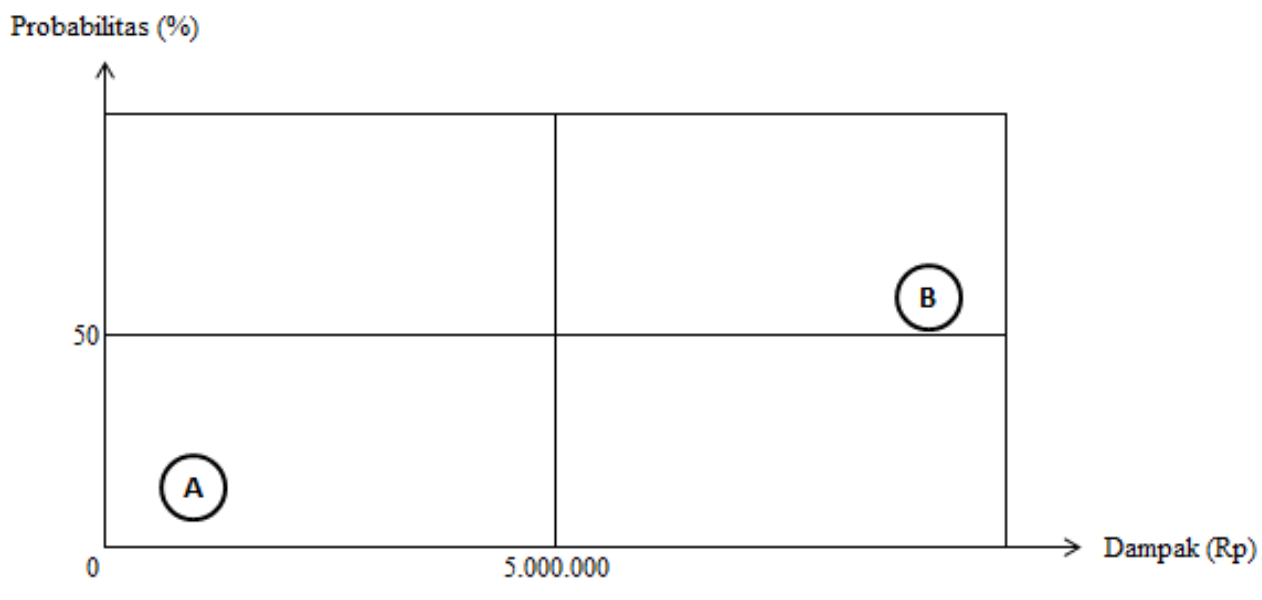

Gambar 2. Peta Risiko Pemetikan Manual

Keterangan :

A $\quad=$ Keterampilan Pemetik

B $\quad=$ Kelelahan Pemetik

Berdasarkan hasil pemetaan, risiko keterampilan pemetik berada pada kuadran empat (KW 4) dan risiko kelelahan tenaga pemetik berada pada kuadran dua (KW 2). Berdasarkan gambar peta risiko keterampilan pemetik pada pemetikan manual terletak pada kuadran tiga. Risiko kelelahan pemetik memiliki probabilitas yang kecil dan dampak yang kecil, sehingga tidak perlu dilakukan strategi mitigasi maupun preventif untuk memperkecil probabilitas dan mengurangi dampak risiko tersebut. Menurut Kusumawati, et.al., (2017), produksi pucuk the pada petik manual rendah diduga disebabkan oekh tenaga petik yang kurang sehingga banyak pucuk teh yang tidak terpetik secara maskimal. 
Strategi alternatif yang digunakan untuk mengurangi risiko kelelahan pada tenaga pemetik adalah gabungan dari strategi mitigasi dan preventif (mencegah terjadinya risiko dan mengurangi kerugian). Kelelahan pada tenaga pemetik diakibatkan oleh kurangnya tenaga pemetik pada setiap kemandoran sehingga pemetik harus melakukan proses pemetikan melampaui waktu kerja (Time over). Ketidakhadiran tenaga kerja pada masa panen (petik) teh menyebabkan pucuk teh menjadi menua (kaboler) dan tidak layak untuk dipetik (sebab pucuk keboler merupakan pucuk teh yang tidak memenuhi syarat dan pada akhirnya tidak dijual ke pabrik). Oleh karena itu, peningkatan kualitas pucuk teh sangatlah bergantung pada ketepatan waktu petik pucuk teh dan ketersediaan tenaga kerja. Strategi pertama yaitu melakukan pemetikan sesuai dengan ketepatan waktu petik dengan menghitung siklus petik sehingga tidak ada keterlambatan pemetikan yang menyebabkan pemetik harus bekerja lebih lama dari waktu yang ditentukan. Strategi kedua untuk menanggulangi kurangnya tenaga kerja adalah dengan menggantikan sistem pemetikan manual menjadi pemetikan mekanik dengan mesin atau semi mekanik menggunakan gunting petik pada saat terjadi pelonjakan produksi. Satu unit mesin pemetikan mekanik dapat menggantikan 25 tenaga kerja pemetikan manual. Sehingga hal tersebut sangat efektif untuk menjawab permasalahan kekurangan tenaga kerja.

\section{KESIMPULAN DAN SARAN}

\section{Kesimpulan}

Perbedaan nilai risiko produksi pemetikan mekanik dan pemetikan manual pada PT Perkebunan Nusantara IX Kebun Semugih adalah 0,09. Nilai risiko produksi daun teh basah pada pemetikan mekanik sebesar 0,76 dan nilai risiko produksi daun teh basah pemetikan manual sebesar 0,67. Perbedaan produktivitas kerja pada pemetikan mekanik dan manual adalah sebesar 24,28 kg/jko. Produktivitas pemetikan mekanik sebesar $31,52 \mathrm{~kg} / \mathrm{jko}$ dan produktivitas pemetikan manual sebesar 7,24 kg/jko. Strategi risiko yang tepat untuk menangani risiko pemetikan mekanik pada sumber risiko keterampilan pemetik yaitu strategi gabungan antara mitigasi dan preventif dengan mengurangi dampak dan 
Ula et.al. / Jurnal Dinamika Sosial Ekonomi Vol.20 No.1, Juni 2019

mencegah risiko itu terjadi, sedangkan risiko kelelahan dan kerusakan mesin tidak dilakukan penanganan strategi. Strategi risiko untuk menangani risiko pemetikan manual pada sumber risiko kelelahan tenaga pemetik menggunakan strategi gabungan antara mitigasi dan preventif, sedangkan risiko keterampilan pemetik tidak dilakukan penanganan strategi.

\section{Saran}

PT Perkebunan Nusantara IX Kebun Semugih dalam upaya mengurangi risiko produksi daun teh basah pada pemetikan mekanik dan manual disarankan untuk melakukan pelatihan keterampilan memetik pucuk teh yang bermutu kepada para tenaga pemetikan serta pengawasan secara instens dari mandor petik. Pada blok pemetikan mekanik perlu dilakukan pemeliharaan yang lebih dibandingkan dengan blok pemetikan manual terutama pada musim kemarau agar tanaman tetap dalam kondisi sehat. Perusahaan perlu melakukan mekanisasi pemetikan untuk menjawab permasalahan kekurangan tenaga kerja pada pemetikan manual.

\section{DAFTAR PUSTAKA}

Dalimoenthe, S. L. dan W. S. Kartawijaya. (1997). Mekanisasi pemetikan. Jurnal Warta Pusat Penelitian Teh dan Kina, 8 (3), 159 - 164.

Herawati, Heny dan Agus Nurawan. (2009). Pengkajian Penggunaan Gunting Petik pada Komoditas Teh di Kecamatan Cikalong Wetan Kabupaten Bandung. AGRITECH, 29 (1), 47-52.

Johan, M.E., B. Sriyadi. (2005). Pemetikan Klon Teh Seri GMB pada Siklus Panjang Menggunakan Gunting. Jurnal Penelitian Teh dan Kina. 8(3), 7278.

Kountur R. (2008). Mudah Memahami Manajemen Risiko Perusahaan. Jakarta (ID): PPM

Kusumawati, Ana dan Angga Triaji W. (2017). Perbandingan Penggunaan Mesin Petik dan Petik Tangan Terhadap Produksi Pucuk Teh di Perkebunan Kayu Aro PTPN VI Kabupaten Kerinci. Yogyakarta. Jurnal Agroteknose. 8 (2), 36-44.

Ongong, J.O., Ochieng, A. 2013. Innovation in the tea industry: the case of kericho tea, Kenya. Global Journal of Management and Business Research. 13(1),11-12.

Sukasman, 1998. Pemetikan Teh dengan Gunting di Perkebunan Teh. Seminar Internal Pusat Penelitian Teh dan Kina, Gambung. 